\title{
Effect of STAT3 decoy oligodeoxynucleotides mediated by ultrasound-targeted microbubbles combined with ultrasound on the growth of squamous cell carcinoma of the esophagus
}

\author{
YAN ZHANG ${ }^{1}$, MEIWU ZHANG ${ }^{1}$, XIAOXIANG FAN $^{1}$, DAFENG MAO $^{1}$, SHUYI LV $^{1}$ and PING CHEN ${ }^{2}$ \\ Departments of ${ }^{1}$ Interventional Therapy and ${ }^{2}$ Gastrointestinal and Minimally Invasive Surgery, \\ Ningbo No. 2 Hospital, Ningbo, Zhejiang 315010, P.R. China
}

Received May 14, 2018; Accepted November 12, 2018

DOI: $10.3892 / \mathrm{ol} .2018 .9814$

\begin{abstract}
Effect of STAT3 decoy oligodeoxynucleotides (ODN) transduced by ultrasound microbubbles combined with ultrasound on the growth of esophageal squamous cell carcinoma and its mechanism were analyzed. EC9706 cells were cultured in vitro and divided into four groups: group $\mathrm{E}$ (ultrasound microbubble + ultrasound irradiation), group $\mathrm{P}$ (liposome + ultrasound irradiation), group C (ultrasound), and group CC (ultrasound microbubbles). Mutant ODNs were used in groups $\mathrm{E}$ and $\mathrm{P}$ and the control group was group $\mathrm{EC}$ and $\mathrm{PC}$, respectively. Immunofluorescence assay and flow cytometry were used to detect the transfection efficiency of each group. MTT colorimetric assay was performed to analyze the inhibition rate in each group. The effect of STAT3 decoy ODN on the proliferation of esophageal squamous carcinoma cells was calculated. Revese transcription-quantitative PCR (RT-qPCR) and western blotting were performed to detect the expression of the STAT signaling pathway downstream of gene expression levels. The model of subcutaneous transplantation of nude mice was used to show the effect of different transfections and STAT3 decoy ODN on the weight and volume of the transplanted tumor in mice. The cell inhibition rate was higher in group $\mathrm{E}$ than in groups $\mathrm{P}(\mathrm{F}=8.382, \mathrm{P}<0.001)$ and $\mathrm{CC}(\mathrm{F}=6.469, \mathrm{P}<0.001)$. Compared with groups $\mathrm{EC}, \mathrm{PC}$ and $\mathrm{C}$, respectively, the mRNA expression of STAT3, bcl-xL and Cyclin D1 decreased in groups E, P and CC ( $\mathrm{F}=5.328$, $\mathrm{P}<0.001)$. The weight and volume of nude mice in groups $\mathrm{E}$, $\mathrm{P}$ and $\mathrm{CC}$ exhibited an inhibitory effect on the weight and volume of nude mice. Ultrasound irradiation combined with ultrasound microbubbles is an effective transfection method.
\end{abstract}

Correspondence to: Dr Ping Chen, Department of Gastrointestinal and Minimally Invasive Surgery, Ningbo No. 2 Hospital, 41 Northwest Street, Ningbo, Zhejiang 315010, P.R. China E-mail: ppb42y@163.com

Key words: ultrasound microbubbles, ultrasound irradiation, STAT3 decoy oligodeoxynucleotides, squamous cell carcinoma of the esophagus
The transfection of STAT3 decoy ODN can significantly inhibit the activity of esophageal squamous cell carcinoma cells and enhance apoptosis of cells, which has potential clinical value.

\section{Introduction}

As the main pathological type of esophageal cancer, esophageal squamous cell carcinoma has led to high morbidity and mortality in China for many years. Its clinical manifestations are mainly progressive dysphagia and difficulties in swallowing food. At present, the clinical treatments for esophageal squamous cell carcinoma are surgery, radiotherapy and chemotherapy. In recent years, with the advancement of social development and medical conditions, the surgical skill of esophageal cancer has been continuously improved, and radiotherapy equipment and novel chemotherapy drugs have also been continuously updated. However, the mortality rate for esophageal squamous cell carcinoma has not been significantly improved. Latest studies have suggested that the 5-year survival rate is only $20 \%$ (1-3). As a result, the treatments for esophageal squamous cell carcinoma need to be improved. Hao et al (4) pointed out that the occurrence and development of esophageal squamous cell carcinoma are associated with multiple risk factors. Apart from dietary habits and chemical factors, gene deletion and abnormal expression should also be considered. As early as 2012, Zhang et al (5) pointed out in a study that STAT3 activation can cause abnormal proliferation and transformation of esophageal squamous carcinoma cells. Moreover, a study conducted by Katsha et al (6) also suggested that the competitor of STAT3, STAT3 decoy oligodeoxynucleotides (ODN), can slow the growth of cancer cells. Therefore, determining how to safely and effectively introduce STAT3 decoy ODN into target cells and target tissues has become a hot spot in recent clinical research. Although conventional viral vectors have certain transfection efficiency, the defects of poor targeting and low safety cannot be ignored. Furthermore, although liposome transfection is relatively common and the technology is widely implemented, transfection efficiency remains low. Ultrasound-targeted microbubbles combined with ultrasound have become a new research direction in China. A large number of studies have confirmed that it can safely and effectively increase gene transfection. However, 
its effect on squamous cell carcinoma through the mediation of STAT3 decoy ODN is rare, and merely few reports have been published worldwide. Therefore, the purpose of the present study was to explore the effect of ultrasound-targeted microbubbles combined with ultrasound on the growth of esophageal squamous cell carcinoma and its mechanisms, in order to provide a new direction for the treatment of esophageal squamous cell carcinoma.

\section{Materials and methods}

Main materials. Human esophageal squamous carcinoma cell line EC9706 was provided by the Chinese Academy of Sciences Cell Bank (Shanghai, China). RPMI-1640 medium and fetal bovine serum were purchased from Gibco (Thermo Fisher Scientific, Inc., Waltham, MA, USA), and the trypsin and MTT kits were purchased from Sigma-Aldrich (St. Louis, MO, USA). The DAB chromogenic reagent kit (PA110) was purchased from Tiangen Biotech Co., Ltd., (Beijing, China), while the RIPA protein lysate (product no. P0013B) and dimethyl sulfoxide (product no. ST038) were manufactured by Biyuntian Biotech Co., Ltd. (Shanghai, China). Rabbit anti-STAT3 polyclonal antibody, mouse anti-p-STAT3 (705-tyrosine phosphorylation site) monoclonal antibody, and horseradish peroxidase-conjugated goat anti-rabbit secondary antibody were purchased from Signalway Antibody LLC (College Park, MD, USA). The ultrasound contrast agent SonoVue (lyophilized preparation) was purchased from Bracco SpA (Milan, Italy), while the Lipofectaine ${ }^{\mathrm{TM}} 2000$ transfection kit for cationic liposomes was obtained from Invitrogen (Thermo Fisher Scientific, Inc.). The ODNs and its mismatch control sequences were designed by Shanghai Shenggong Biological Engineering Co., Ltd. (Shanghai, China). All base sequences were modified by total phosphorothioation. The STAT3 decoy ODN sequence was 5'-CATTTCCCGTA AATC-3' and 5'-CATTTACGGGAAATG-3', and was labeled with FITC. The double-stranded mutant ODN control sequence was 5'-CATTTCCTTAAATC-3' and 5'-GATTTAAGGGAA ATG-3'.

The main instruments include an Olympus fluorescence inverted microscope (Olympus Corporation, Tokyo, Japan), an ultrasound therapeutic apparatus (Taizhou People's Hospital, Taizhou, China), an ABI 7500 real-time fluorescence quantitative PCR system (Applied Biosystems; Thermo Fisher Scientific, Inc.), an Annexin V-FITC/PI apoptosis kit (Hangzhou MultiSciences [Lianke] Biotech Co., Ltd., Hangzhou, China), a CGZZ Ultrasonic gene transfection instrument (Ultrasonographic Image Research Institute, Chongqing Medical University, Chongqing, China; ultrasonic transmitting frequency, 300-1,000 kHz; sound intensity range, 0.25-2.50 W/cm), and a Synergy HT Multi-dection microplate reader (BioTek Instruments, Inc., Winooski, VT, USA).

The study was approved by the Ethics Committee of Ningbo No. 2 Hospital (Ningbo, China).

Cell culture. Cells were cultured in RPMI-1640 medium $(100 \mu \mathrm{g} / \mathrm{ml}$ of streptomycin $+100 \mathrm{U} / \mathrm{ml}$ of penicillin) containing $10 \%$ high-quality fetal bovine serum, and maintained at a specific condition of $37^{\circ} \mathrm{C}$ with $5 \% \mathrm{CO}_{2}$ saturation humidity. Then, cells that adherently grew were closely observed, and the culture fluid was changed every two days. When $\sim 80 \%$ confluence was reached, cells were digested with trypsin $(0.25 \%)$ and passaged. Exponentially growing cells were selected for subsequent experiments.

Preparation of microbubbles. The diameter of the ultrasound contrast agent SonoVue was 2-5 $\mu \mathrm{m}$, and the average diameter $\sim 2.5 \mu \mathrm{m}$. The surface had phospholipids, and was filled with SF6. Before implementation, $5 \mathrm{ml}$ of $0.9 \%$ physiological saline was used to dissolute and dilute the SonoVue, and vigorously shaken until the freeze-dried powder completely dissolved into a microbubble suspension. According to previous experiments, the optimal microbubble concentration was $20 \%$.

Groups for the experiment. The present study was divided into three groups: the experimental group, the positive control group and the blank control group. The experimental group included the following sub-groups: Group E, STAT3 Decoy ODN + ultrasound microbubble contrast agent mixed solution + ultrasound irradiation; Group EC, mutant ODN + ultrasonic microbubble contrast agent mixed solution + ultrasonic irradiation. The positive control groups were as follows: Group P, STAT3 decoy ODN + liposomal mixture + ultrasound irradiation; Group PC, mutant ODN + liposomal mixture + ultrasound irradiation. The blank control groups were as follows: Group C, STAT3 decoy ODN + ultrasound irradiation; Group CC, STAT3 decoy ODN + ultrasound microbubble contrast agent mixed solution.

Cell transfection and ultrasonic irradiation. The sense and antisense STAT3 decoy ODN was solubilized with pH 8.0 Tris- $\mathrm{HCl}$ EDTA solution (1 $\mathrm{mmol} / \mathrm{l})$, respectively. Then, this was annealed at $90^{\circ} \mathrm{C}$ to form a double strand, keeping the temperature down at $5^{\circ} \mathrm{C}$ every $15 \mathrm{~min}$, and the reactant mixture was stored at $4^{\circ} \mathrm{C}$.

The transfection operations for groups E and EC were as follows: serum-free RPMI-1640 nutrient solution was used to adjust the concentration of ODN and $1 \mathrm{ml}$ of ultrasonic microbubble suspension to $100 \mathrm{pmol}$. The above two liquids were respectively mixed, gently shaken, and subsequently placed on ice for $20 \mathrm{~min}$. The STAT3 decoy ODN (mutant ODN)microbubble mixture was mixed with cells at a density of $1 \times 10^{5}$ while being exposed to ultrasound (frequency, $1 \mathrm{MHz}$; irradiation intensity, $0.5 \mathrm{~W} / \mathrm{cm}^{2}$; duration time, $10 \mathrm{sec}$; interval, $10 \mathrm{sec}$; total irradiation time, $1 \mathrm{~min})$. After $6 \mathrm{~h}$ of reaction, the sealing membrane was removed, and the medium containing $10 \%$ fetal bovine serum was replaced by incubating at $37^{\circ} \mathrm{C}$ in a $5 \% \mathrm{CO}_{2}$ incubator.

For groups $\mathrm{P}$ and $\mathrm{PC}$, liposome transfection was performed, according to the kit instructions. Then, 2-4 $\mu \mathrm{g}$ of STAT3 decoy ODN/mutant ODN (100 pmol) and $5 \mu \mathrm{l}$ of Lipofectamine were respectively dissolved in serum-free and antibiotic-free medium, and mixed were thoroughly. Afterwards, this was allowed to stand for $5 \mathrm{~min}$, and was incubated at room temperature for $20 \mathrm{~min}$. Then, cells were diluted to adjust the density to $1 \times 10^{5}$. Next, the STAT3 decoy ODN-liposome mixture was mixed with cells and placed at $37^{\circ} \mathrm{C}$. Then, ultrasonic irradiation was performed at the same conditions as above, incubated for another $6 \mathrm{~h}$, and the RPMI-1640 medium containing 10\% fetal bovine serum was replaced for further culture. 
For group C, 100 pmol of ODN was mixed with EC9706 esophageal squamous carcinoma cells at a density of $1 \times 10^{5}$, and subjected to ultrasound irradiation under the above conditions. After $6 \mathrm{~h}$, the serum that contained the RPMI-1640 medium was replaced. For group CC, the same procedure was performed as that in groups E and EC, except for the ultrasound irradiation.

Detection after transfection. After $48 \mathrm{~h}$ of operating, according to the above, the cells were observed and photographed under an inverted fluorescence microscope (magnification, $x 400$ ). Then, 10 fields were randomly selected from each slide, and the transfection rate was calculated by the ratio of the number of green fluorescence cells and the number of total cells.

Detection of cell apoptosis by flow cytometry. Cells were collected after digestion, cultured for $24 \mathrm{~h}$, washed with prechilled $4^{\circ} \mathrm{C}$ PBS twice, and the supernatant was discarded. Then, $70 \%$ ethanol was used to fix cells. Next, the samples were centrifuged at $5,013 \mathrm{x}$ g for $10 \mathrm{~min}$ at $28^{\circ} \mathrm{C}$ and resuspended in $500 \mu \mathrm{l}$ of binding buffer to a cell density of $1 \times 10$ cells $/ \mathrm{ml}$. Subsequently, $5 \mu \mathrm{l}$ of FITC-labeled Annexin V mixture and $10 \mu \mathrm{l}$ of propylene iodide (PI; $1 \mu \mathrm{g} / \mathrm{ml}$ ) solution were added and carefully mixed. After $15 \mathrm{~min}$ of dark reaction at room temperature, $400 \mu \mathrm{l}$ of $1 \mathrm{X}$ binding buffer was added. After the full reactions, BD Accuri ${ }^{\mathrm{TM}}$ C6 Flow Cytometer (BD, Loveton Circle, USA) was used to detect $1 \times 10^{4}$ cells per sample.

Cell survival curve measurement by MTT assay. The log phase growth of EC9706 cells was diluted to $1 \times 10^{8} / 1$ of cell suspension, and inoculated on 96-well plates at $200 \mu 1$ per well. Then, the diluted STAT3 decoy ODN, mutant ODN, liposomes and ultrasonic microbubble mixture was added into the corresponding wells after $24 \mathrm{~h}$ of incubation. Each group was set up with six duplicate wells, and $150 \mu$ l of culture medium was added. The control group consisted of an equal volume of dimethyl sulfoxide and serum-free medium without any treatment. The change in culture fluid at 12, 24, 48 and $72 \mathrm{~h}$ after the start of the culture observed, and $20 \mu$ l of MTT $(5 \mathrm{mg} / \mathrm{ml})$ was simultaneously added at room temperature for another $4 \mathrm{~h}$. Then, the supernatant was carefully discarded, and $150 \mu 1$ of DMSO was added. Subsequently, dimethyl sulfoxide $(150 \mu \mathrm{l})$ was added, and lightly shaken for 10 min until the crystals were dissolved. The absorbance (A) of each well was measured using a microplate reader at $490 \mathrm{~nm}$. The formula was: Cell inhibition rate $\%=($ A control group $-\mathrm{A}$ experimental group $) / \mathrm{A}$ control group $\mathrm{x} 100 \%$.

Revese transcription-quantitative PCR (RT-qPCR). Cells were lysated with TRIzol reagent. Then, the lysate was transferred to a centrifuge tube, chloroform was added, and the supernatant was taken after shaking and centrifugation at 12,000 $\mathrm{x}$ g for $15 \mathrm{~min}$ at $4^{\circ} \mathrm{C}$. Next, the upper RNA was extracted and an equal volume of isopropanol was added. The mixture was centrifuged at $12,000 \mathrm{xg}$ for $10 \mathrm{~min}$ at $4^{\circ} \mathrm{C}$ after mixing well. Then, the precipitate was collected, washed with 75\% ethanol, and air-dried and dissolved in DEPC to synthesize the cDNA by reverse transcription. The internal reference gene was $\beta$-actin. The reaction conditions were as follows: pre-denaturation at $95^{\circ} \mathrm{C}$ for $2 \mathrm{~min}$, denaturation at $95^{\circ} \mathrm{C}$ for $30 \mathrm{sec}$, annealing at $60^{\circ} \mathrm{C}$ for $30 \mathrm{sec}$, extension at $72^{\circ} \mathrm{C}$ for 1 min with 35 cycles, and finally, extension at $72^{\circ} \mathrm{C}$ for $10 \mathrm{~min}$. The $\mathrm{Ct}$ values of the internal reference genes and the genes of the respective groups were measured, and the relative expression levels of the target gene were calculated using the formula $2^{-\Delta \Delta \mathrm{Cq}}(7)$. The experiment was repeated three times. In the present experiment, the internal reference gene and target gene primer sequences are presented in Table I.

Western blotting. Each group of cells was washed three times with pre-chilled PBS. The RIPA lysate was added to extract the total tissue protein, according to protein kit instructions. The BCA kit was used to quantitatively analyze the protein concentration. Then, $20 \mu \mathrm{g}$ of cellular total protein was respectively taken from each group for $10 \%$ SDS-PAGE separation. The semi-dry method was used to separate the protein, followed by transmembrane at a constant-voltage electrophoresis of $100 \mathrm{~V}$. Then, $5 \%$ skim milk powder was used for blocking for $\sim 1 \mathrm{~h}$, and reacted overnight with p-STAT3 primary antibody (dilution, 1:250; cat. no. 4905) and STAT3 primary antibody (dilution, 1:600; cat. no. BF0374) for $2 \mathrm{~h}$ at a temperature of $4^{\circ} \mathrm{C}$. Subsequently, the membrane was washed with TBST, and goat anti-mouse IgG secondary antibody (dilution, 1:1,000; cat. no. F0106B) added at $37^{\circ} \mathrm{C}$ and incubated for $1 \mathrm{~h}$. The color was developed using a DAB kit and analyzed using Image $\mathbf{J}$ software. The experiment was repeated three times. The expression level of each detection factor was evaluated using the gray ratio of the target gene bands and $\beta$-actin bands.

Nude mouse model of subcutaneous transplantation tumor. Forty BALB/c female nude mice, aged 4-6 weeks with mean body mass $19.35 \pm 0.46 \mathrm{~g}$ were provided by Beijing Vital River Laboratory Animal Technology Co., Ltd. (Art. no. 401). During the feeding process, the temperature was maintained between $24-26^{\circ} \mathrm{C}$ with a suitable humidity $(55-70 \%)$, free access to food and water and a daily $12 \mathrm{~h}$ light/dark cycle. Before the experiment, all the mice were adaptively fed for one week. After being anaesthetized via inhalation with $2 \%$ isoflurane, the mice were placed in the supine position and were depilated for ultrasound irradiation. The EC9706 single cell suspension was prepared and resuspended with PBS. Then, cell density was adjusted to $5 \times 10^{7}$ cells $/ \mathrm{ml}$. All treatments were performed on a clean bench. Subsequently, $75 \%$ alcohol was used to partially sterilize the mice. Under sterile conditions, $0.2 \mathrm{ml}$ of a single cell suspension was subcutaneously injected on the right side. Tumors formed after one week of cell inoculation. When the tumors grew to $\sim 100 \mathrm{~mm}^{2}$, mice with strong tumor growth were selected and sacrificed. Then, the necrotic tissue was removed, washed with physiological saline, cut into $2-\mathrm{mm}^{3}$ uniform pieces, and inoculated on the right back of the nude mice. The animals were kept under the conditions of SPF with unlimited feeding. Mice were observed after 10 days. A total of 30 nude mice with a tumor size of $\sim 100-200 \mathrm{~mm}^{3}$ were selected and randomly divided into six groups, with five mice in each group. Mice in the experimental group were slowly injected by each mixture (all, $0.25 \mathrm{ml}$ ) using a 1-ml syringe through the tail vein, while mice in the control group were injected with an equal volume of saline. After the injection, the ultrasound machine was immediately used three times, except for the CC group (output, $0.5 \mathrm{~W} /$ $\mathrm{cm}^{2}$; duration, $20 \mathrm{sec}$; interval, $20 \mathrm{sec}$ ). After the end of irradiation, mice were routinely reared, and the length and width of 
Table I. Primer sequences of RT-qPCR.

\begin{tabular}{llcc}
\hline Primers & & Sequences (5'-3') & Size (bp) \\
\hline STAT3 & F: GGAGGAGGCATTCGGAAAG & R: TCGTTGGTGTCACACAGAT & 110 \\
Cyclin D1 & F: CTTCATTCTCCTTGTTGTTGGT & R: GATTATTGGGGTATAAAATCCTCT & 163 \\
Bcl-xL & F: TGACGTGGACATCCGCAAAG & R: CTGGAAGGTGGACAGCGAGC & 211 \\
$\beta$-actin & F: GGCATCGTGATGGACTCCG & R: GCTGGAAGGTGGACAGCGA & 138 \\
\hline
\end{tabular}

F, forward; R, reverse.
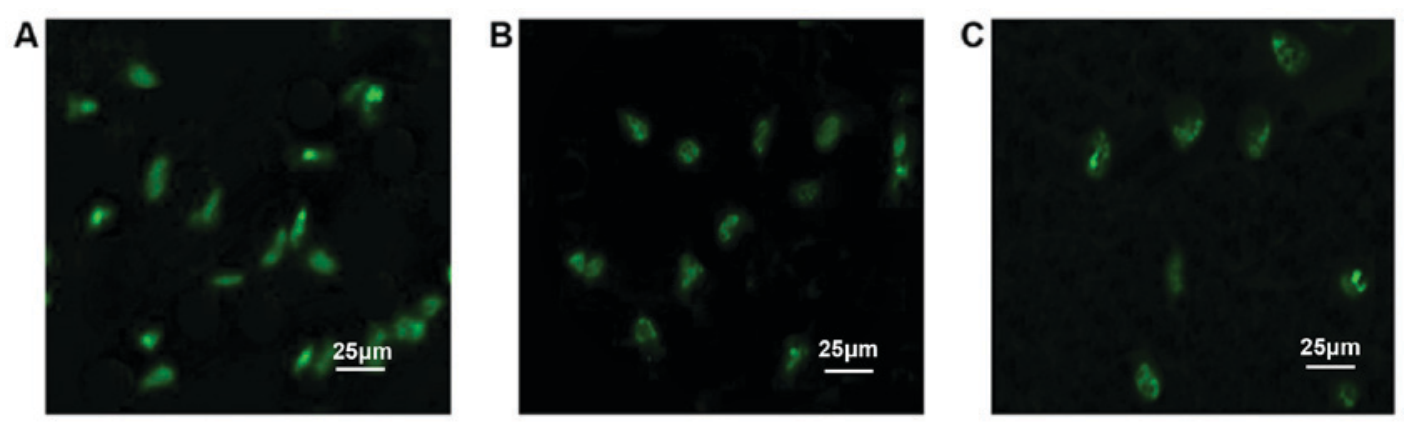

Figure 1. Analysis of immunofluorescence results after transfection of STAT3 decoy ODN. (A) The detection results of E group after fluorescence transfection. (B) The detection results of $\mathrm{P}$ group after fluorescence transfection. (C) The detection results of CC group after fluorescence transfection. ODN, oligodeoxynucleotides.

the transplanted tumor were measured every three days using a vernier caliper. Tumor volume $=$ tumor length $\mathrm{x}$ width ${ }^{2} \mathrm{x} 1 / 2$. The experiment ended at 15 days after inoculation, and the nude mice were sacrificed by cervical dislocation. The tumors of the nude mice were excised and weighed to calculate for the tumor inhibition rate. The tumor inhibition rate $\%=$ (tumor mass of the control group - tumor mass of the experimental group)/tumor mass of the control group $\times 100 \%$.

Statistical analysis. The data obtained from the experiment were analyzed using SPSS 19.0 software (IBM Corp., Armonk, NY, USA). Quantitative data were expressed as mean \pm standard deviation (mean $\pm \mathrm{SD}$ ). Variance analysis was used to determine the immunofluorescence and flow cytometry results after transfection in each group. Pairwise comparison was performed using the SNK-q test. Repeated calculation of variance was performed to analyze the difference in the inhibition rate of the different groups of cells at corresponding time-points, and explore the effect of the overexpression by different methods to transfect STAT3 decoy ODN on the proliferation of cancer cells. At the same time, variance analysis was used to evaluate the RT-qPCR detection and western blotting results. Furthermore, the SNK-q test was used to analyze the differences in the expression levels of gene products in each group, thereby exploring the possible mechanism of STAT3 decoy ODN.

\section{Results}

Detection of transfection efficiency using an inverted fluoroscope. At $48 \mathrm{~h}$ after transfection, green fluorescence was

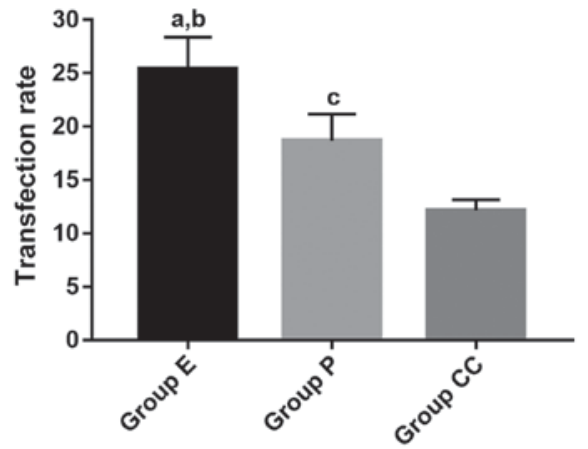

Figure 2. Comparison of the transfection rate of STAT3 decoy ODN in each group. ${ }^{\text {a }} \mathrm{P}<0.05$, compared with groups $\mathrm{P}$ and $\mathrm{E}$; ${ }^{\text {b }} \mathrm{P}<0.05$, compared with groups $\mathrm{CC}$ and $\mathrm{E}$; ${ }^{\mathrm{P}}<0.05$, compared with groups $\mathrm{CC}$ and $\mathrm{P}$. ODN, oligodeoxynucleotides.

observed in the E, P and CC groups. Most of the antisense STAT3 ODNs labeled with FITC entered the cells, and were mainly located in the nucleus. However, the fluorescence intensity and quantity were different. After comparison, it was found that the E group had higher fluorescence intensity and quantity (Fig. 1), while this was slightly weaker in the $\mathrm{CC}$ group than in the $\mathrm{P}$ group. The fluorescence transfection rates of these three groups were as follows: E group, $25.39 \pm 1.05 \%$; P group, 18.68 $\pm 2.34 \%$; CC group, $12.15 \pm 2.27 \%$. The difference was statistically significant $(\mathrm{F}=3.737, \mathrm{P}=0.014)$. Obvious fluorescent markers were not revealed in the rest of the groups (Fig. 2).

Flow cytometry analysis results. The flow cytometry results are presented in Fig. 3. The successful transfection of 

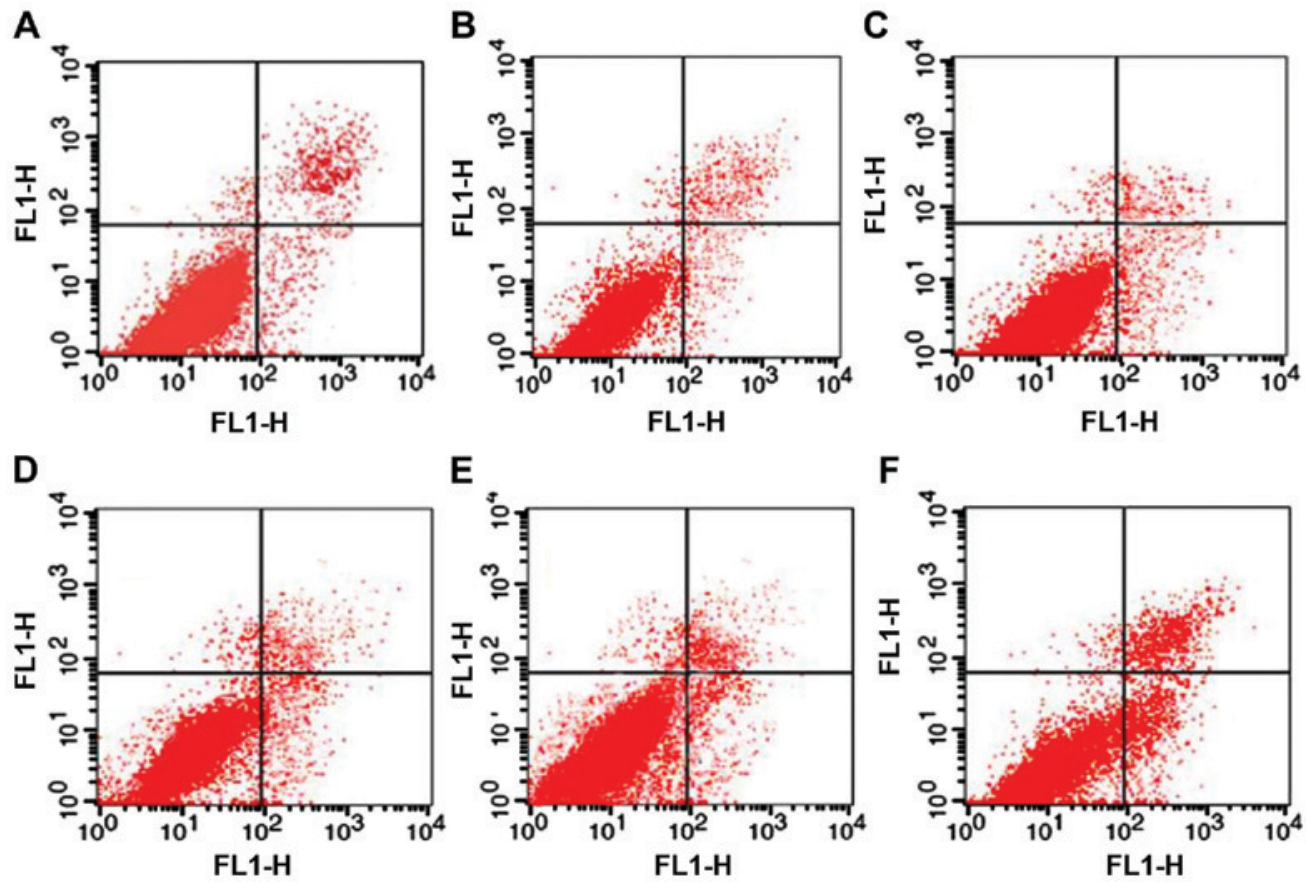

Figure 3. Analysis of flow cytometry results after transfection of STAT3 decoy ODN. (A) Group EC apoptosis test results. (B) Group PC apoptosis test results. (C) Group C fluorescence detection results after transfection. (D) Group CC apoptosis test results. (E) Group P apoptosis test results. (F) Group E fluorescence detection results after transfection. ODN, oligodeoxynucleotides.

STAT3 decoy ODN promoted apoptosis in EC9706 cells. Furthermore, the number of apoptotic cells increased by $10.70 \pm 2.64$ and $6.44 \pm 3.03 \%$ in the $\mathrm{E}$ and $\mathrm{P}$ groups, respectively, when compared with the corresponding control groups. The apoptosis rate in group E increased by $6.48 \pm 2.00 \%$, when compared with group P. The apoptosis rate in the $\mathrm{CC}$ group was only $5.34 \pm 1.28 \%$. Furthermore, the apoptosis rates in the $\mathrm{EC}, \mathrm{PC}$ and $\mathrm{C}$ groups were $2.36 \pm 0.22,1.71 \pm 0.13$, and $2.00 \pm 0.97 \%$, respectively. The variance analysis revealed $\mathrm{F}=1.483, \mathrm{P}=0.329$. Furthermore, there was no statistical difference among groups (Figs. 3 and 4).

Changes in cell proliferation activity in each group over time. The MTT assay results revealed that the proliferation activities of cells were inhibited to varying degrees in groups $\mathrm{E}, \mathrm{P}$ and $\mathrm{CC}$, and the maximum inhibition rate was present at $72 \mathrm{~h}$ after culture. Repeated variance analysis among groups revealed that the inhibition rate was higher in group $\mathrm{E}$ than in group $\mathrm{P}$ $(\mathrm{F}=8.382, \mathrm{P}<0.001)$ and group $\mathrm{CC}(\mathrm{F}=6.469, \mathrm{P}<0.001)$. Next, the inhibition rate of each group was compared under different time-points. As shown in Table II, compared with the corresponding control groups, the value-added inhibitory rates of groups E, $\mathrm{P}$ and $\mathrm{CC}$ increased at 24, 48 and $72 \mathrm{~h}$ after transfection, and the difference was statistically significant $(\mathrm{P}<0.05)$. Furthermore, group $\mathrm{E}$ had the lowest value-added activity at the above time-points $(\mathrm{P}<0.05)$, while the value-added inhibition rate of groups EC, $\mathrm{PC}$ and $\mathrm{C}$ slightly fluctuated over time. The value changes were not obvious, and the difference was not statistically significant $(\mathrm{P}>0.05)$ (Table III).

Detection of relative $m R N A$ expression in each group by $R T-q P C R$. The PCR results revealed that the relative content of STAT3 mRNA in groups E, P and CC decreased

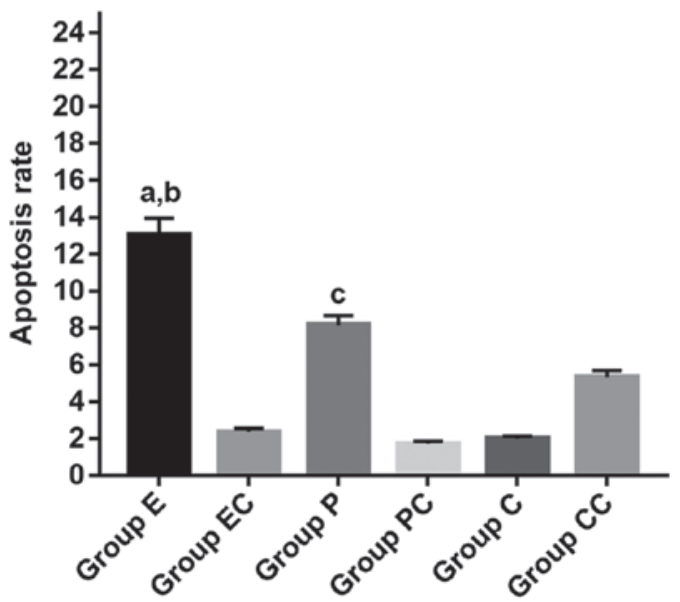

Figure 4. Comparison of apoptosis rates in each group. ${ }^{a} \mathrm{P}<0.05$, compared with groups $\mathrm{P}$ and $\mathrm{E} ;{ }^{b} \mathrm{P}<0.05$, compared with groups $\mathrm{CC}$ and $\mathrm{E} ;{ }^{\mathrm{c}} \mathrm{P}<0.05$, compared with groups $\mathrm{CC}$ and $\mathrm{P}$.

after transfection with STAT3 decoy ODN. At the same time, the mRNA levels of bcl-xL and Cyclin D1 were also downregulated. The variance analysis revealed that the difference was statistically significant $(\mathrm{F}=5.328, \mathrm{P}<0.001)$. Furthermore, the comparison between groups revealed that the expression levels of the STAT3, Cyclin D1 and bcl-xL gene products in group E were greater than those in group P, and these relative expression levels decreased by $12.9,14.6$ and $11.3 \%$, respectively, with significant differences $(\mathrm{P}<0.05)$. In group E, STAT3 mRNA was downregulated by $17.1 \%$, Cyclin D1 mRNA was downregulated by $20.1 \%$, and bcl-xL mRNA was downregulated by $15.4 \%$, when compared with group CC. The rest of the groups did not reveal any significant changes (Fig. 5). 
Table II. Comparison of cell inhibition rates in each group at different time-points.

\begin{tabular}{lcccc}
\hline Groups & $12 \mathrm{~h}$ & $24 \mathrm{~h}$ & $48 \mathrm{~h}$ & $72 \mathrm{~h}$ \\
\hline Group E & $0.203 \pm 0.043$ & $0.248 \pm 0.036^{\mathrm{a}, \mathrm{b}}$ & $0.459 \pm 0.043^{\mathrm{a}, \mathrm{b}}$ & $0.584 \pm 0.031^{\mathrm{a}, \mathrm{b}}$ \\
Group EC & $0.177 \pm 0.025$ & $0.182 \pm 0.055$ & $0.173 \pm 0.036$ & $0.156 \pm 0.030$ \\
Group P & $0.194 \pm 0.031$ & $0.225 \pm 0.027^{\mathrm{c}}$ & $0.348 \pm 0.027^{\mathrm{c}}$ & $0.432 \pm 0.041^{\mathrm{c}}$ \\
Group PC & $0.192 \pm 0.026$ & $0.202 \pm 0.052$ & $0.177 \pm 0.031$ & $0.186 \pm 0.047$ \\
Group C & $0.206 \pm 0.039$ & $0.209 \pm 0.043$ & $0.276 \pm 0.035$ & $0.339 \pm 0.035$ \\
Group CC & $0.195 \pm 0.024$ & $0.198 \pm 0.020$ & $0.202 \pm 0.027$ & $0.184 \pm 0.050$ \\
\hline
\end{tabular}

$\mathrm{F}_{\mathrm{E}-\mathrm{P}}=8.382, \mathrm{P}_{\mathrm{E}-\mathrm{P}}<0.001 ; \mathrm{F}_{\mathrm{E}-\mathrm{CC}}=6.469, \mathrm{P}_{\mathrm{E}-\mathrm{CC}}<0.001 ; \mathrm{F}_{\mathrm{CC}-\mathrm{P}}=4.332, \mathrm{P}_{\mathrm{CC}-\mathrm{P}}=0.002 .{ }^{\mathrm{a}} \mathrm{P}<0.05$, compared with groups $\mathrm{P}$ and $\mathrm{E}$; ${ }^{\mathrm{b}} \mathrm{P}<0.05$, compared with groups $\mathrm{CC}$ and $\mathrm{E}$; ${ }^{\mathrm{P}}<0.05$, compared with groups $\mathrm{CC}$ and $\mathrm{P}$.

Table III. The difference in mean mass and tumor inhibition rate of xenografts in nude mice.

\begin{tabular}{|c|c|c|c|c|c|c|c|c|}
\hline Variables & Group E & Group EC & Group P & Group PC & Group C & Group CC & $\mathrm{F}\left(\chi^{2}\right)$ & P-value \\
\hline Tumor quality (g) & $0.553 \pm 0.029^{\mathrm{a}, \mathrm{b}}$ & $0.846 \pm 0.038$ & $0.572 \pm 0.023^{c}$ & $0.874 \pm 0.026$ & $0.796 \pm 0.011$ & $0.715 \pm 0.033$ & 6.938 & $<0.001$ \\
\hline Inhibition rate $(\%)$ & 27 & 4.50 & 19 & 2.30 & 6.20 & 12 & & \\
\hline
\end{tabular}

SNK-Q test: ${ }^{\mathrm{a}} \mathrm{P}<0.05$, compared with groups $\mathrm{P}$ and $\mathrm{E}$; ${ }^{\mathrm{b}} \mathrm{P}<0.05$, compared with groups $\mathrm{CC}$ and $\mathrm{E}$; ${ }^{\mathrm{P}} \mathrm{P}<0.05$, compared with groups $\mathrm{CC}$ and $\mathrm{P}$.

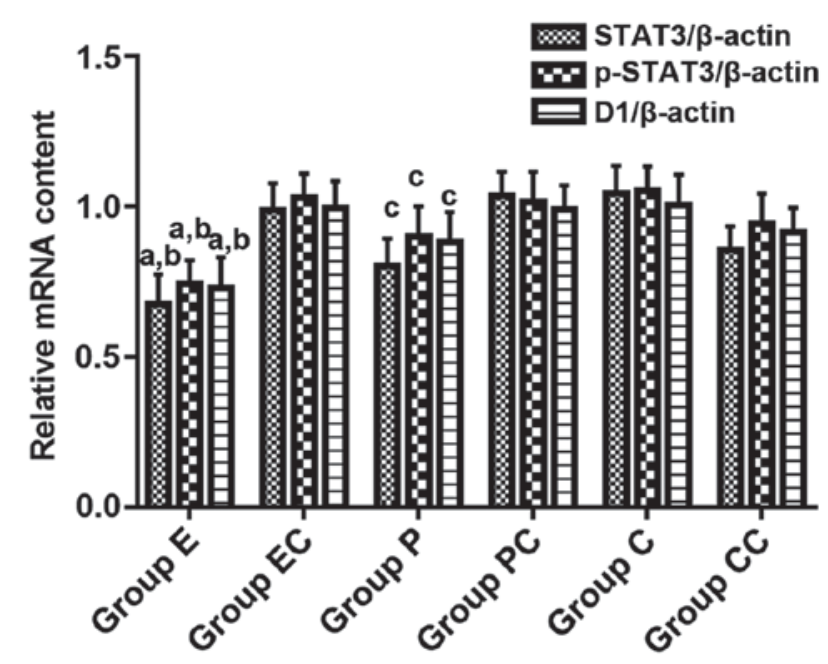

Figure 5. Relative mRNA expression levels in each group after transfection. ${ }^{\mathrm{a}} \mathrm{P}<0.05$, compared with groups $\mathrm{P}$ and $\mathrm{E}$; ${ }^{\mathrm{b}} \mathrm{P}<0.05$, compared with groups $\mathrm{CC}$ and $\mathrm{E} ;{ }^{\mathrm{C}} \mathrm{P}<0.05$, compared with groups $\mathrm{CC}$ and $\mathrm{P}$.

STAT3 and p-STAT3 protein content assay in each group. Western blotting results revealed that after $72 \mathrm{~h}$ of transfection, the contents of STAT3 and p-STAT3 proteins significantly decreased in groups $\mathrm{E}, \mathrm{P}$ and $\mathrm{CC}$, when compared with the other three groups. The ultrasound contrast agent, the ultrasound contrast agent combined with ultrasound irradiation, and liposome all significantly reduced the expression of STAT3 and p-STAT3, and the difference was statistically significant $(\mathrm{F}=3.795, \mathrm{P}=0.032)$. Furthermore, the protein expression level was the lowest in group $\mathrm{E}$, followed by the $\mathrm{P}$ group, while the protein expression levels in groups EC, PC and $\mathrm{C}$ were similar (P>0.05) (Figs. 6 and 7).

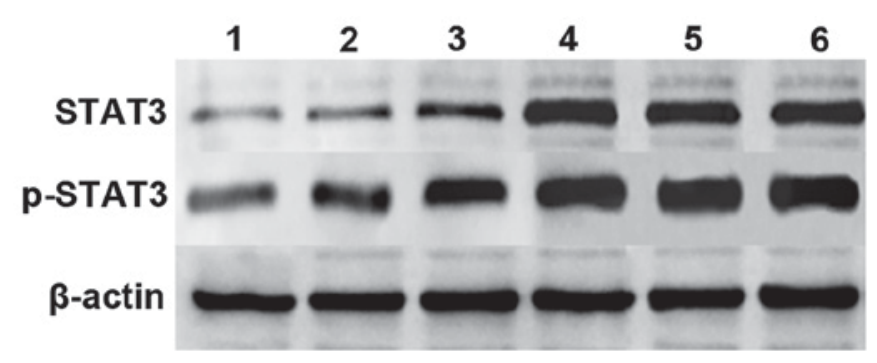

Figure 6. Analysis of western blotting results in each group. Lane 1, E group; lane 2, P group; lane 3, CC group; lane 4, EC group; lane 5, PC group; lane $6, \mathrm{C}$ group.

Effectofdifferent transfectionmethods on tumor growth activity in nude mice. The growth changes of the transplanted tumors in each group of nude mice were observed after inoculating and culturing with different transfection methods. From the overall growth trend, the tumor volume of nude mice in groups EC, PC and $\mathrm{C}$ grew rapidly, and the amplitude was large. Furthermore, the tumor volume in nude mice in the corresponding control groups exhibited a growing trend, but the growth was slow. The volume of tumor growth in group E was the lowest, followed by group P. In addition, the analysis of changes in tumor volume at the different time-points in each group revealed that the transplanted tumors in each group shared a similar volume on the 3rd day after inoculation, and the difference was not statistically significant $(\mathrm{P}>0.05)$. However, on the 9 th day after inoculation, the volume of transplanted tumors in each group of nude mice came to be significantly different, and the volume in groups E, P and CC was significantly smaller than that in the corresponding control groups $(\mathrm{P}<0.05)$. At 9 th, 12th and 15 th day after inoculation, the tumor volume in group $\mathrm{E}$ was the 


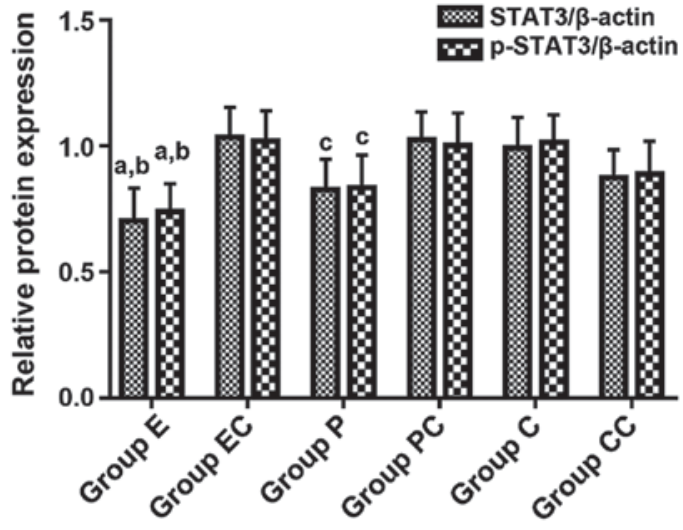

Figure 7. STAT3 and p-STAT3 protein level results in each group. ${ }^{\mathrm{a}} \mathrm{P}<0.05$, compared with groups $\mathrm{P}$ and $\mathrm{E}$; ${ }^{\mathrm{b}} \mathrm{P}<0.05$, compared with groups $\mathrm{CC}$ and $\mathrm{E}$; ${ }^{\mathrm{c}} \mathrm{P}<0.05$, compared with groups $\mathrm{CC}$ and group $\mathrm{P}$.

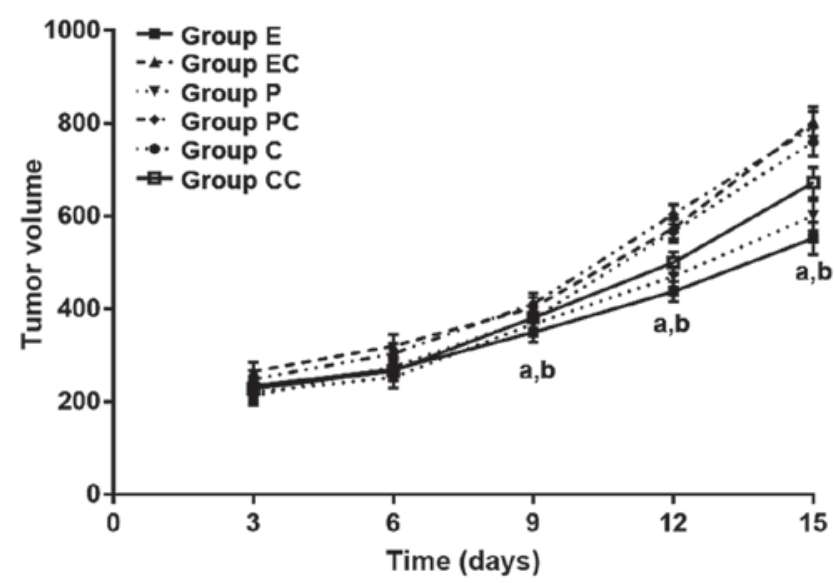

Figure 8. Comparison of the size of xenografts in nude mice. ${ }^{\text {a }} \mathrm{P}<0.05$, compared with groups $\mathrm{P}$ and $\mathrm{E} ;{ }^{\mathrm{b}} \mathrm{P}<0.05$, compared with groups $\mathrm{CC}$ and $\mathrm{E}$.

lowest, when compared with groups $\mathrm{P}$ and $\mathrm{CC}$, and the difference was statistically significant $(\mathrm{P}<0.05)$. After stripping the tumors of each group, a statistically significant difference was shown in the mass of these tumors $(\mathrm{F}=6.938, \mathrm{P}<0.001)$. The tumors in group $\mathrm{E}$ had the lowest mass and the highest inhibition rate $(\mathrm{P}<0.05)$. The tumor masses in groups $\mathrm{P}$ and $\mathrm{CC}$ were smaller than that in the rest of the groups, and the inhibition rate was significantly increased $(\mathrm{P}<0.05)$ (Fig. 8).

\section{Discussion}

Multiple studies have indicated that the sustained activation of STAT3 has a close relationship with the occurrence and development of various tumors such as gastric, esophageal, breast, and liver cancer (8). Blocking the continuous activation of STAT3 has been considered to be an effective treatment, and STAT3 decoy ODN is a continuously mature blocking method that can weaken downstream biochemical reactions by downregulating the hyperphosphorylation of intracellular STAT3 protein to inhibit the proliferation activity of tumor cells $(9,10)$. Therefore, the competitive blocking method of inhibiting tumor proliferation through the transfection of STAT3 decoy ODN has been highly valued. Determining how to safely and efficiently transfer STAT3 decoy ODN into cells has become a new challenge. The commonly used gene transfection carriers in the laboratory are mainly viral vectors and non-viral vectors. However, the safety and immunogenicity of viral vectors are difficult to guarantee. The liposomes and plasmids commonly found in non-viral vectors are easily degraded. Hence, transfection efficiency is not high, and the therapeutic effect is poor $(11,12)$. In recent years, ultrasound microbubbles combined with ultrasound irradiation has been widely used as a new transfection tool in basic research. Kodama et al (13) demonstrated that it can significantly improve transfection efficiency in vivo. Furthermore, the study conducted by Masuda et al (14) also pointed out that the use of ultrasound contrast agents has no toxic side effects on the human body. Compared with viral vectors, this safety problem can be solved. In addition, the ultrasonic instrument is convenient to operate, and can accurately control the energy output index. Furthermore, it can be used for different cells to match the relatively accurate safety parameter range, which is better than electroporation (physical method). Generally, it does not cause damage to tissues (15). However, few studies have been conducted on the effects on esophageal squamous cell carcinoma cells, in which ultrasound microbubbles combined with ultrasound irradiation transfected with STAT3 decoy ODN and conventional carrier-liposomes were compared.

The present study compared several transfection methods. The positive control group commonly used liposome combined with ultrasound irradiation. In order to exclude the interference from other factors such as ODN, mispaired ligands were used as intragroup controls. From the results of the immunofluorescence detection, liposomes, ultrasound microbubbles and ultrasound microbubbles combined with ultrasound irradiation can successfully transfect ODNs into cancer cells, indicating that liposomes and ultrasound microbubbles are all effective transfer tools. Among these, ultrasound microbubbles combined with ultrasound irradiation had the highest transfection rate, and liposome combined ultrasound irradiation had a lower transfection rate. Czarnota et al (15) suggested that the rational use of ultrasound irradiation can enhance the ability of cells to take up carrier-gene complexes, while enhancing the ability of the nucleus to take up genes. This may be one of the reasons for the significant increase in ultrasound microbubble transfection efficiency under ultrasound irradiation. The flow cytometry and MTT assay analysis results revealed that the three groups of cancer cells successfully transfected with STAT3 decoy ODN had an increased rate of apoptosis at the early stages, and cell proliferation activity gradually decreased, suggesting that the antisense transfection was successful and STAT3 decoy ODN was active. The STAT3 ODNs transfected into cells can downregulate the expression and activation of STAT3 protein, resulting in the subsequent expression of related genes that can promote apoptosis of esophageal cancer cells and inhibit their proliferation (16). Apoptosis in the E group was the highest, but the proliferation activity was the lowest, suggesting that ultrasonic microbubbles combined with ultrasound irradiation is a more effective and safe method, compared with traditional lipofection. However, further studies are needed.

P-STAT3 is formed by persistently activated STAT3, and plays a role in upregulating the expression of bcl-xL and Cyclin D1 after binding the target gene in the nucleus. The change in STAT3 expression interferes with the process of cell 
proliferation and differentiation, reduces apoptosis of tumor cells and causes carcinogenesis (17). The present study found that the expression levels of STAT3 and p-STAT3 protein in cancer cells transfected with STAT3 decoy ODN significantly decreased. At the same time, bcl-xL and Cyclin D1 mRNA levels were also significantly downregulated. Therefore, STAT3 decoy ODN has an inhibitory effect on esophageal squamous carcinoma cells grown in vitro. A study conducted by Liu et al (17) demonstrated that antisense ODN STAT3 can inhibit tumor cell activity, but does not have any adverse effects on normal cells. Therefore, it can be used as an effective tumor-targeting therapy, providing new ideas for human antitumor therapy. The protein and mRNA expression in each group was shown to be lower in the $\mathrm{E}$ group, and later in the positive control $\mathrm{P}$ group. Therefore, it can be considered that ultrasound microbubbles combined with ultrasound irradiation can reduce STAT3 phosphorylation to inhibit the expression of downstream anti-apoptotic genes. Hence, it has value in the prevention and treatment of esophageal squamous cell carcinoma. The nude mouse model with transplanted tumor suggested that ultrasound microbubbles combined with ultrasound irradiation transfected with STAT3 decoy ODN had inhibitory effects on the growth of transplanted tumors in nude mice, and its intensity of action was higher than that of liposome-transfected STAT3 decoy ODN.

In conclusion, the present study confirms that ultrasound irradiation combined with ultrasound microbubbles is an effective transfection method. Transfection of STAT3 decoy ODN can significantly inhibit the activity of esophageal squamous carcinoma cells and enhance apoptosis. Hence, it has a potential clinical therapeutic value.

\section{Acknowledgements}

Not applicable.

\section{Funding}

This study was supported by Medical Key Discipline of Ningbo Oncology 2016-B05.

\section{Availability of data and materials}

The datasets used and/or analyzed during the present study are available from the corresponding author on reasonable request.

\section{Authors' contributions}

YZ, MZ, SL and PC contributed to the concept and design of the study. XF and DM were responsible for the collection and analysis of the data. SL and PC wrote and revised the manuscript. All authors read and approved the final manuscript.

\section{Ethics approval and consent to participate}

The study was approved by the Ethics Committee of Ningbo No. 2 Hospital (Ningbo, China).

\section{Patient consent for publication}

Not applicable.

\section{Competing interests}

The authors declare that they have no competing interests.

\section{References}

1. Ikeda G, Isaji S, Chandra B, Watanabe M and Kawarada Y: Prognostic significance of biologic factors in squamous cell carcinoma of the esophagus. Cancer 86: 1396-1405, 1999.

2. Dawsey SM, Fleischer DE, Wang GQ, Zhou B, Kidwell JA, Lu N, Lewin KJ, Roth MJ, Tio TL and Taylor PR: Mucosal iodine staining improves endoscopic visualization of squamous dysplasia and squamous cell carcinoma of the esophagus in Linxian, China. Cancer 83: 220-231, 1998.

3. Tanaka H, Kanda M, Koike M, Iwata N, Shimizu D, Ezaka K, Sueoka S, Tanaka Y, Takami H, Hashimoto R, et al: Adherens junctions associated protein 1 serves as a predictor of recurrence of squamous cell carcinoma of the esophagus. Int J Oncol 47: 1811-1818, 2015.

4. Hao JJ, Lin DC, Dinh HQ, Mayakonda A, Jiang YY, Chang C, Jiang Y, Lu CC, Shi ZZ, Xu X, et al: Spatial intratumoral heterogeneity and temporal clonal evolution in esophageal squamous cell carcinoma. Nat Genet 48: 1500-1507, 2016.

5. Zhang Y, Du XL, Wang CJ, Lin DC, Ruan X, Feng YB, Huo YQ, Peng H, Cui JL, Zhang TT, et al: Reciprocal activation between PLK1 and Stat 3 contributes to survival and proliferation of esophageal cancer cells. Gastroenterology 142: 521-530.e3, 2012.

6. Katsha A, Arras J, Soutto M, Belkhiri A and El-Rifai W: AURKA regulates JAK2-STAT3 activity in human gastric and esophageal cancers. Mol Oncol 8: 1419-1428, 2014.

7. Livak KJ, Schmittgen TD: Analysis of relative gene expressiondata using real-time quantitative PCR and the 2(-Delta DeltaC(T)) Method. Methods 25: 402-8, 2001.

8. Yang Z, Guo L, Liu D, Sun L, Chen H, Deng Q, Liu Y, Yu M, Ma Y, Guo N, et al: Acquisition of resistance to trastuzumab in gastric cancer cells is associated with activation of IL-6/STAT3/Jagged-1/Notch positive feedback loop. Oncotarget 6: 5072-5087, 2015.

9. Kopechek JA, Carson AR, McTiernan CF, Chen X, Hasjim B Lavery L, Sen M, Grandis JR and Villanueva FS: Ultrasound targeted microbubble destruction-mediated delivery of a transcription factor decoy inhibits STAT3 signaling and tumor growth. Theranostics 5: 1378-1387, 2015.

10. Shi K, Xue J, Fang Y, Bi H, Gao S, Yang D, Lu A, Li Y, Chen Y and Ke L: Inorganic kernel-reconstituted lipoprotein biomimetic nanovehicles enable efficient targeting 'Trojan Horse' delivery of STAT3-decoy oligonucleotide for overcoming TRAIL resistance. Theranostics 7: 4480-4497, 2017.

11. Burnham LA, Jaishankar D, Thompson JM, Jones KS, Shukla D and Tiwari V: Liposome-mediated herpes simplex virus uptake is glycoprotein-D receptor-independent but requires heparan sulfate. Front Microbiol 7: 973, 2016.

12. Yamada Y, Hashida M and Harashima H: Hyaluronic acid controls the uptake pathway and intracellular trafficking of an octaarginine-modified gene vector in CD44-positive and CD44negative cells. Biomaterials 52: 189-198, 2015.

13. Kodama T, Aoi A, Watanabe Y, Horie S, Kodama M, Li L, Chen R, Teramoto N, Morikawa H, Mori S, et al: Evaluation of transfection efficiency in skeletal muscle using nano/microbubbles and ultrasound. Ultrasound Med Biol 36: 1196-1205, 2010.

14. Masuda N, Maruyama A,Eguchi T, Hirakawa T and Murakami Y: Influence of microbubbles on free radical generation by ultrasound in aqueous solution: Dependence of ultrasound frequency. J Phys Chem B 119: 12887-12893, 2015.

15. Czarnota GJ: Ultrasound-stimulated microbubble enhancement of radiation response. Biol Chem 396: 645-657, 2015.

16. Xuan X, Li S, Lou X, Zheng X, Li Y, Wang F, Gao Y, Zhang H, $\mathrm{He} \mathrm{H}$ and Zeng Q: Stat3 promotes invasion of esophageal squamous cell carcinoma through up-regulation of MMP2. Mol Biol Rep 42: 907-915, 2015.

17. Liu R, Liao J, Yang M, Sheng J, Yang H, Wang Y, Pan E, Guo W, $\mathrm{Pu}$ Y, Kim SJ, et al: The cluster of miR-143 and miR-145 affects the risk for esophageal squamous cell carcinoma through. PLoS One 7: e33987, 2012. 